\title{
ULTRATRACE DETERMINATION OF CURIUM
}

\author{
James V. Beitz \\ Argonne National Laboratory
}

Work directed toward detection of curium at near single atom levels is being undertaken as a part of the Argonne National Laboratory Advanced Concepts Project that is funded by the U. S. Department of Energy, Office of Arms Control and Nonproliferation. This work promises thousand-fold improvement in detection sensitivity in comparison with the best current method. The technique being developed can provide a signature method of detecting clandestine reprocessing of recently irradiated uranium targets. In the new method, a pulsed near-ultraviolet laser saturates a fingerprint-like absorbing band of trivalent curium ions in aqueous solution to optimize detection sensitivity. Time- and wavelength-resolution of the resulting curium emission ensures high specificity in this nondestructive analysis method.

Curium is a man-made element that is generated primarily as the isotope curium-242 during production of fissile material via neutron irradiation of uranium targets. By allowing the curium-242 in a given sample to partially decay and then determining the total curium content of the sample again, the curium-242 fraction can be quantified. The foundation for this work is fundamental spectroscopic and photophysics research on trivalent curium that was carried out in the Chemistry Division of Argonne National Laboratory under the auspices of the Heavy Elements Chemistry Program of the U. S. Department of Energy, Office of Basic Energy Sciences, Division of Chemical Sciences. 


\section{DISCLAIMER}

Portions of this document may be illegible in electronic image products. Images are produced from the best available original document. 


\title{
ULTRATRACE DETERMINATION OF CURIUM
}

\author{
James V. Beitz \\ Argonne National Laboratory
}

Development of a method for detection of curium at near single atom levels is being undertaken as a part of the Advanced Concepts Project at Argonne National Laboratory with funding from the U. S. Department of Energy, Office of Arms Control and Nonproliferation. Ultratrace determination of curium, with the ability to quantify the fraction that is curium-242, provides a signature method of detecting clandestine reprocessing of recently irradiated uranium targets. Curium initially present in any of a variety of materials such as air filters, solid or liquid process waste, soil, flora, or fauna can be recovered via current chemical separations processing techniques. Using the ultratrace method being developed, such recovered curium will be quantified with thousand-fold higher sensitivity than the best currently available method which is alpha counting. This high sensitivity arises because, on average, a given trivalent curium $\left(\mathrm{Cm}^{3+}\right)$ ion can emit a very large number of fluorescence photons before alpha decay occurs.

In the method being developed, a near-ultraviolet laser is used to saturate a fingerprintlike optical absorption band of $\mathrm{Cm}^{3+}$ in aqueous solution and thereby optimize the probability that the $\mathrm{Cm}^{3+}$ ions in the sample will fluoresce following each laser pulse. Population of a lower-lying metastable excited electronic state of $\mathrm{Cm}^{3+}$ occurs via nonradiative decay. The orange light emitted by the metastable state is collected, spectrally filtered with high efficiency, and detected using a cooled photodetector. Additional enhancement of fluorescence will be achieved by solvent deuteration. Combining optical saturation with time- and wavelength resolution of fluorescence emission from $\mathrm{Cm}^{3+}$ will result in very high sensitivity and excellent assurance that the species being detected is $\mathrm{Cm}^{3+}$. Because only trivalent curium is stable in 
aqueous solution, the quantity determined is the total curium content of the sample. Analysis for total curium in a sample solution using this method is inherently nondestructive.

Curium is a man-made element that is generated during production of fissile material via neutron irradiation of uranium targets. The curium isotope primarily produced is $\mathrm{Cm}-242$ whose half-life is 163 days. Due to its short-lived character, there is no long term accumulation of $\mathrm{Cm}$ 242 in the environment and the intrinsic curium background is very low. Conversely, the very high specific alpha activity of $\mathrm{Cm}-242$ enhances release of curium during processing of irradiated uranium targets. In the method being developed, the $\mathrm{Cm}-242$ fraction of total curium will be determined by allowing decay of $\mathrm{Cm}-242$ to occur and then carrying out a second determination of the total curium content of the sample.

This work builds on past fundamental spectroscopic and photophysics studies in the Chemistry Division of Argonne National Laboratory. Those systematic studies on the 5f-state energy level structure, transition intensities, and fluorescence dynamics of trivalent actinides ions in light and heavy water solution provided that the basis and insight essential to the present work. The prior basic research studies were carried out under the auspices of the Heavy Elements Chemistry Program of the U. S. Department of Energy, Office of Basic Energy Sciences, Division of Chemical Sciences.

\section{DISCLAIMER}

This report was prepared as an account of work sponsored by an agency of the United States Government. Neither the United States Government nor any agency thereof, nor any of their employees, makes any warranty, express or implied, or assumes any legal liability or responsibility for the accuracy, completeness, or usefulness of any information, apparatus, product, or process disclosed, or represents that its use would not infringe privately owned rights. Reference herein to any specific commercial product, process, or service by trade name, trademark, manufacturer, or otherwise does not necessarily constitute or imply its endorsement, recommendation, or favoring by the United States Government or any agency thereof. The views and opinions of authors expressed herein do not necessarily state or reflect those of the United States Government or any agency thereof. 